\title{
O PROTAGONISMO DA LINGUAGEM NA PRODUÇÃO DE CORPOS, DISCURSOS E PRÁTICAS DE RESISTÊNCIA
}

José Sena ${ }^{1}$

Resumo: Orientado pela perspectiva performativa Butleriana, o artigo debate o protagonismo que a linguagem assume na produção de corpos, discursos e práticas de resistência. Com atenção às relações de saber-poder-subjetividade implicadas nas práticas sociais, e aos conceitos de performance/performatividade, argumenta-se que essa visada não-essencialista contribui para adensar analíticas de contextos sociais/linguísticos contemporâneos. Desse modo, o texto chama atenção para a relevância da performance enquanto prática de linguagem mobilizadora de processos reflexivos que podem gerar alternativas diante de problemáticas sociais que geram sofrimento humano.

Palavras-chave: Linguagem. Performance. Performatividade. Corpo. Resistência.

Abstract: Guided by the Butlerian performative perspective, the article debates the role that language assumes in the production of bodies, discourses and resistance practices. With attention to the relations of knowledge-power-subjectivity implied in social practices, and to the concepts of performance / performativity, it is argued that this non-essentialist view contributes to densifying analyzes of contemporary social / linguistic contexts. In this way, performance as a language practice will be understood as a mobilizer of reflexive processes that can generate alternatives in the face of social problems that generate human suffering.

Keywords: Language. Performance. Performativity. Body. Resistance.

\section{Introdução}

Baseado em uma pesquisa mais ampla que investiga as disputas metapragmáticas no cuidado em saúde sexual de sujeitos das dissidências do gênero/sexualidades em um território da Amazônia brasileira (SENA, 2016; 2017; 2018; 2020), o presente artigo empreende um debate teórico sobre o protagonismo que a linguagem assume nas práticas sociais, em que dinâmicas corpóreo-discursivas mobilizam, em constante tensionamento, regimes de saberpoder-subjetividade (FOUCAULT, 1984; 1996; 1999; 2000). Os dados gerados no contexto etnográfico da referida pesquisa apontam para a proeminância da linguagem não apenas nos processos de produção de significados, mas também na construção performativa (BUTLER, 1990; MOITA LOPES, 2006; PEREZ-NAVARRO, 2008) de mundos sociais, com efeitos sobre corpos/subjetividades e estratégias de resistência diante de regimes de dominação.

\footnotetext{
${ }^{1}$ Doutor em Linguística Aplicada pela Universidade Federal do Rio de Janeiro (UFRJ), Rio de Janeiro, Brasil. Esta pesquisa foi financiada com bolsa de doutorado pelo Conselho Nacional de Desenvolvimento Científico e Tecnológico (CNPq). E-mail: senaufrj@gmail.com
} 
PERcursos Linguísticos • Vitória (ES) •v. 10 •n. 25 • 2020 • ISSN: 2236-2592 • Dossiê:

Discursos de resistência e corpos (re)existentes

Para empreender o debate, posiciono, primeiramente, uma visada epistêmica. Ao apresentar três paradigmas centrais na história dos estudos da linguagem, precisamente as visões mentalista, realista e pragmática, argumento por uma visada relativista a qual alicerça sua visão de linguagem com base na ação ou nas práticas. Em seguida, aprofundo alguns aspectos fundamentais da teoria performativa da linguagem, na qual articulo a reflexão entre performatividade/performance e o lugar do corpo, do desejo, da agência e da resistência em tal teorização (BUTLER, 1990; 1993; 1997; 1998; 2003; 2010; PINTO, 2002; 2007; 2009; SALIH, 2015; FURLIN, 2013). A proposta é percorrer, pontualmente, as influências que constituem a perpsectiva performativa bluteriana, no intento de situar o caráter de ação da linguagem na construção de entendimentos, corpos e resistências.

\section{Uma visada Pragmática}

Conforme indicam as pesquisas de Gazpar Neto (2008), Pocahy (2011), Braz (2010), Souza (2012), Barreto (2012), Souza (2013), Silva (2015) diferentes estudos neste século XXI têm reforçado uma agenda de produção de conhecimento sobre modos de vida dissidentes e suas práticas de resistência de norte ao sul do Brasil. No campo da linguagem não tem sido diferente. Estudos engajados nas práticas corpóreo-discursivas e produção de entendimentos sobre sexo, sexualidade, gênero e interseccionalidades, como raça, classe social, etnia etc., em diferentes plataformas de produção textual/discursiva, têm mostrado o protagonismo da linguagem na produção de conhecimento sobre essas demandas da vida social (MOITA LOPES 2002; 2006; BORBA, 2014; 2015; SANTOS FILHO, 2012; GUIMARÃES, 2014; BONFANTE, 2016; SILVA, 2017; CAMARGO, 2019; SENA, 2020).

Podemos dizer que o avanço dos estudos sobre o corpo e as identidades sexogenerificadas na contemporaneidade é demanda, também, do que se convencionou chamar de virada discursiva/narrativa (BASTOS; BIAR, 2015; FERREIRA, 2016) a qual teve efeitos diretos sobre a produção de conhecimento científico de modo geral, e sobre o campo de estudos da linguagem de modo particular. Impulsionada por uma série de mudanças que deslocaram as certezas da racionalidade objetiva, comum à lógica modernista (SANTOS, 2008), para a compreensão de que nossas práticas sociais são efeitos discursivos (FOUCAULT, 1996; BUTLER, 1990), a virada discursiva/narrativa deixa ver uma profunda crise paradigmática decorrente de uma variedade de fatores divididos entre sociais e teóricos, os quais percorrem desde a superação da dicotomia cultura/natureza até a compreensão de 
PERcursos Linguísticos • Vitória (ES) •v. 10 •n. 25 • 2020 • ISSN: 2236-2592 • Dossiê:

Discursos de resistência e corpos (re)existentes

que, seja nas ciências naturais ou sociais, a produção de conhecimento está implicada (CAMARGO JÚNIOR, 1994).

Esse movimento instaura o que temos vivido na contemporaneidade em termos de ampliação na circulação de textos, discursos e experiências, mobilizando intensos processos de reflexividade sobre nós mesmos (GIDDENS, 1991), com efeitos importantes sobre esferas locais-globais. Bauman (2008), Moita Lopes (2013), dentre outros, têm chamado esses tempos de fluidez de modernidade recente. Se é verdade que a modernidade silenciou uma série de demandas sociais de sujeitos que subalternizados (MIGNOLO, 2008) viram suas histórias e direitos interditados ou apagados, na modernidade recente uma atitude política passa a ser viabilizada pela possibilidade reflexiva que ela mobiliza.

Como bem exploraram Bauman e Briggs (2003), uma ideologia modernista orientou diferentes campos do saber e a linguagem desempenhou papel crucial nesse processo, pois a crença em uma linguagem neutra, imparcial, "verdadeira" fundamentou os modos como a ciência por séculos enunciou e orientou seus modos de produzir conhecimento. No campo da saúde sexual, por exemplo, Paula Treichler já problematizava que a epidemia da aids era sobretudo uma "epidemia da significação", apontando para o protagonismo da linguagem na produção de saberes, na relação entre senso comum e ciência (TREICHLER, 1987). Isso implica dizer que "os pressupostos metafísicos, os sistemas de crenças, os juízos de valor não estão antes, nem depois da explicação científica da natureza ou da sociedade. São parte integrante dessa mesma explicação" (SANTOS, 2008, p. 83).

No campo dos estudos linguísticos, paradigmas filosóficos ou ideologias linguísticas (BAUMAN; BRIGGS, 2003) buscam, de diferentes modos, dar explicações sobre a relação da linguagem com a questão do sentido e com a questão da verdade. Assim, entendimentos essencialistas e fundamentalmente abstratos sobre a linguagem e sua relação com o "estado de coisas no mundo" decorre das ideologias linguísticas realistas, em que "o significado de uma expressão linguística é a parcela da realidade que ela identifica", e mentalista, para a qual a linguagem "representa acontecimentos mentais compartilhados entre falantes e ouvintes" (MARTINS, 2004, p. 442).

Um debate fundamental nesse contexto foi $\mathrm{o}$ proposto por Valentin Voloshinov (1997) e o círculo de Bakhtin, no início do século XX, o qual critica duas orientações epistemológicas para defender sua tese de que a realidade fundamental da língua é a interação verbal. Assim, ao criticar o que ele identificou como objetivismo abstrato, orientação que defende o fato linguístico, o sistema, independente do sujeito falante; e o 
PERcursos Linguísticos • Vitória (ES) •v. 10 •n. 25 • 2020 • ISSN: 2236-2592 • Dossiê:

Discursos de resistência e corpos (re)existentes

subjetivismo idealista, o qual restringe a fala ao domínio do psiquismo individual, o autor russo funda as bases de uma perspectiva sociointeracionista, que se alinha ao paradigma pragmático (MARTINS, 2004).

Se no campo específico dos estudos linguísticos os paradigmas realistas e mentalistas se mantiveram como principais orientadores das teorizações sobre a linguagem, sustentando uma visada essencialista, é com o paradigma pragmático, numa visada relativista, que muitas problemáticas sobre a linguagem serão estudadas com base nos usos e nas práticas sociais (SILVERSTEIN, 1993; 2003).

Essa reflexão é fundamental para entendermos que as epistemologias linguísticas não são o limite para nossas pesquisas (MOITA LOPES, 1994; 2012; 2006; PINTO, 2015), umas vez que o linguístico demanda o sociocultural e o político, nos conduzindo ao exame de processos sociais que ganham relativa estabilidade na linguagem, ou seja, os significados não estão dados no artefato linguístico, no significante, mas são condicionados no fluxo dos usos em nossos mundos sociais. Como diria Fabrício (2006), precisamos estar atentos aos "jogos de linguagem" que enredam epistemes, discursos e regimes de verdade, sem perder de vista que estamos implicados nesse processo de produção de significados.

Com esse debate ${ }^{2}$ sob minha atenção, é no âmbito de uma Linguística Aplicada Indisciplinar que enuncio as reflexões presentes neste artigo. Seguindo uma ampla agenda de debates teóricos, epistemológicos e aplicados sobre a relação entre linguagem e a vida social, a perspectiva Indisciplinar (MOITA LOPES, 2006) tem coberto uma variedade de temas e abordagens que durante muito tempo foram deixados de lado no âmbito dos estudos linguísticos, mas que no paradigma emergente (SANTOS, 2008) vem ganhando proeminência, e chama atenção para uma visada performativa da linguagem (AUSTIN, 1990;

\footnotetext{
${ }^{2}$ Na relação com o paradigma pragmático é possível situar diferentes teorizações que, se por um lado possuem peculiaridades conceituais e disciplinares, têm em comum a relação com a perspectiva das práticas e dos usos. Por exemplo, a sociologia de Bauman (2008), ao estabeler sua crítica à modernidade e a uma série de certezas e estabilidades político-culturais-societais, situa nossa condição contemporânea como líquida, instável, insegura e, por tanto, ancorada nos fluxos. Nesse sentido, embora orientados por uma visão culturalista e de influência marxista, Voloshinov (1997) e o Círculo de Bakhtin estão preocupados com os usos, apontando para o lugar privilegiado da língua na disputa por significados e ideologias no mundo social. Do mesmo modo, a perspectiva performativa bluteriana, conforme aprofundarei, decorre das influências do debate feminista, da psicanalálise (FREUD, 1996, por exemplo), da filosofia da linguagem, da perspectiva pós-estruturalista com Derrida (1991; 1973) e Foucault (1999), dentre outros, mas sempre convergindo para uma visão de linguagem entendida como ação na vida social. É assim que para o linguista aplicado Moita Lopes (2006; 2012; 2013) é interessante pensar a linguagem a partir de outras teorizações e outros campos disciplinares, o que ele tem chamado Indisciplinaridade. Articular esse debate em diálogo com essas diferentes visões se insere precisamente nesse exercício indisciplinar de confrontar algumas verdades que se pretendem universais e politizar os usos e as escolhas teóricas que elegermos em nossas pesquisas.
} 
PERcursos Linguísticos • Vitória (ES) •v. 10 •n. 25 • 2020 • ISSN: 2236-2592 • Dossiê:

Discursos de resistência e corpos (re)existentes

DERRIDA, 1991; 1973; BUTLER, 1990; 1997), a qual dá relevo ao protagonismo que a linguagem assume na produção de corpos, discursos e práticas de resistência.

\section{Performatividade}

Dentre as diferentes teorizações, de orientação pragmática, emergentes ao longo do século XX, são as articulações teóricas mobilizadas pelo filósofo inglês John Austin que fundam as bases de uma visada performativa (AUSTIN, 1990). Ao questionar a forma como o problema da verdade vinha sendo encarado pela filosofia clássica, Austin elabora sua teoria dos atos de fala, argumentando, no início de suas palestras, que para além dos enunciados constatativos ou declarativos, ou seja, enunciados que validam valores de verdadeiro ou falso a uma dada proposição, há os enunciados performativos, enunciados que praticam ação (OTTONI, 2002; PINTO, 2002; 2007).

A partir da oitava conferência de seu curso, contudo, Austin (1990) abandona essa diferença, argumentando que todo uso linguístico é performativo (LOXLEY, 2007). Apesar disso, Austin não faz nenhuma correção ou acréscimo à exclusão de sua teorização dos usos "parasitári[os]" (p. 36) da linguagem, como o teatro e as piadas, sob a alegação de que não seriam usos "sério[s]" (p. 36), visto que se baseiam em roteiros pré-determinados. É exatamente essa dependência de roteiros ou scripts, no entanto, que Derrida (1991) destaca como central a todo uso linguístico, questionando assim a existência de enunciados totalmente novos ou inatos.

Representante da vertente de pensamento denominada desconstrutivismo, localizada na tradição pós-estruturalista, Derrida foi um crítico das concepções metafísicas, e elaborou sua teoria tendo como principal contraponto o estruturalismo. Différance (1991) é o termo que Derrida utiliza para explicar que a linguagem é um sistema aberto de signos, uma vez que o signo continuamente diferido na diferença implica a condição do sentido, o qual se constitui em uma presença que nunca pode ser definida em definitivo, ou seja, a différance "é o que faz com que o movimento da significação não seja possível a não ser que cada elemento dito "presente", que aparece sobre a cena da presença, se relacione com outra coisa que não ele mesmo" (idem, p.45). Este aspecto é relevante, pois é sobre o modo de tratamento da estrutura e do sujeito presentes nas teorizações de Austin (1990), que Derrida (1991) estabelecerá o foco de sua crítica: 
a presença consciente dos locutores ou receptores participando na efetuação de um performativo, a sua presença consciente e intencional na totalidade da operação implica teleologicamente que nenhum resto escape à totalização presente (DERRIDA, 1991, p. 364).

A crítica de Derrida (1991) chama atenção primeiramente à originalidade das ideias de Austin (1990), onde reconhece que há uma importante inovação quanto à noção de comunicação que a teoria dos atos de fala inaugura. A comunicação aqui não é mero transporte de significados cristalizados, mas sim processo de produção de significados mediante atos ou ações de fala (DERRIDA, 1991; PINTO, 2002; 2007; 2009). Entretanto, a noção de sujeito intencional e de condições de realização total do ato de fala, contradiz a visão pragmática que o conceito de performatividade ergue ao colocar no centro da produção de significados a ação na/pela linguagem.

É desse modo que os sentidos só existem em deslocamento: cada signo ou conceito aponta para outro signo/conceito que aponta para outro, ad infinitum. O sentido é assim relacional e sempre sujeito a ambivalência, ambiguidades, ou seja, a presença do referente é sempre adiada (DERRIDA, 1991; 1973). No centro do debate, a capacidade de movimentação da unidade de significação supera qualquer entendimento essencialista e cristalizado do significado, do contexto e de suas condições de realização mediante o ato de fala. Esse deslocamento abala, também, a ideia de uma intencionalidade do sujeito, como consciente e dono de todos os seus atos. O que está em jogo é o movimento da produção de significados sempre que o ato de fala opera uma ação. Aqui nem o significado, nem o contexto, nem os sujeitos estão livres da mudança e instabilidade envolvidas no processo de significação.

Trata-se dos conceitos de citação e iterabilidade na linguagem defendidos por Derrida (1991; 1973), com base nos quais toda 'unidade de significação' só ganha o estatuto de unidade significável quando pode ser citada para além de seu contexto de referência 'primária'. Embora ela (a unidade de significação) cite entendimentos possíveis decorrentes de sua história de uso, sua emergência em uma nova situação de comunicação, pode alterar seu entendimento, inclusive pode alterar o próprio contexto.

"Repetir até ficar diferente",, a iterabilidade, segundo Derrida, é o princípio fundamental da linguagem. É desse modo que o autor francês insiste no pressuposto de que os performativos devem ser entendidos com base na iterabilidade, sendo eles a realização do enunciado como possibilidade de atualização e mesmidade, visto que

\footnotetext{
${ }^{3}$ Conforme enunciou Manoel de Barros em seu poema "Uma didática da Invenção".
} 
É necessário que [o signo ou unidade de significação] seja repetível - iterável - na ausência absoluta do destinatário ou do conjunto empiricamente determinável dos destinatários. Esta iterabilidade - (iter, de novo, viria de itara, outro em sânscrito, e tudo o que se segue pode ser lido como exploração desta lógica que liga a repetição à alteridade) estrutura a própria marca de escrita, qualquer que seja aliás o tipo de escrita (DERRIDA, 1991, p. 356)

Esse entendimento da linguagem tem implicações sobre a produção da verdade e do sujeito, uma vez que ao revogar o discurso sobre a origem de uma determinada significação, coloca em causa a complexidade dessa produção, agora entendida na dinâmica da comunicação social e da produção de significados, o que requer entendimentos sobre aspectos locais e históricos implicados em tais processos.

Para aprofundar essa reflexão, destaco do relato etnográfico, produzido na pesquisa que contextualiza o presente debate (SENA, 2020), uma pequena narrativa que ajuda a visibilizar como esse processo se constitui na sutileza da prática social cotidiana. A narrativa foi baseada na experiânecia etnográfica por mim vivida no contexto urbano de uma cidade da Amazônia Atlântica.

Atravesso uma das ruas do centro da cidade de mini-short, batom vermelho, cabelos longos ao vento e meu corpo de ombros largos e pênis. Não abro a boca, apenas caminho. Um grupo de homens, exibindo signos corpóreos de masculinidade hegemônica, cruza meu caminho. Poucos segundos após esse encontro, suas performances passam a incluir a emissão de um som específico, gutural áspero com entonação ascendente, semelhante ao som de uma arara: ['harr"] ['harr"]. Segundo a cultural local, esse som é emitido exclusivamente por humanos machos, supostamente heterossexuais, quando querem interpelar, histericamente, sujeitos como eu, uma bicha. No imaginário heteronormativo, a gay rasgada deveria ser eu, mas o rasgo no silêncio da rua era emitido por esses supostos humanos machos heterossexuais que se travestiam em arara: homens-bicho para identificar homens-bicha (SENA, 2020, p. 32).

Em uma cena curtíssima atravessando uma rua na Amazônia Atlântica, a linguagem produz corpos, identidades, sujeitos, aliás, produz relações de poder. Embora 'de boca fechada', sem nenhum movimento verbal, meu corpo emitia pistas semióticas que o tornava inteligível. Esse processo de compreensão que era feito através de pistas indexicais ${ }^{4}$, como "mini-short", "batom vermelho", "cabelos longos", "corpo de pênis", "ombros largos", apontam indexicalmente para um repertório de sentidos constituído socioculturalmente sobre

${ }^{4}$ Pistas indexicais (WORTHAM, 2001) são signos que indicam (PEIRCE, 1977) significados sobre um estado de coisas no mundo e que produzem (SILVERSTEIN, 1993; 2003), de uma certa maneira, esse estado de coisas no mundo. 
PERcursos Linguísticos • Vitória (ES) •v. 10 •n. 25 • 2020 • ISSN: 2236-2592 • Dossiê:

Discursos de resistência e corpos (re)existentes

o que é ser uma bicha. Uma relação complexa entre o sujeito, a linguagem e o corpo, entendidos aqui como inseparáveis, ou seja, um amalgama sujeito-linguagem-corpo também se configura (SILVERSTEIN, 1993; 2003; GUIMARÃES; MOITA LOPES, 2017).

É assim que minha experiência em campo social, com meu corpo saturado de significações que desobedecem às normas heterossexuais da masculinidade hegemônica vigente, evidencia a produção da diferença quando difiro, - i.e., simultaneamente, me diferencio de e desloco - com a performance corporeo-discursiva que opero, signos historicamente cristalizados do que seja se comportar como um homem. Ao performar uma bicha, eu desobedeço à norma heterossexual e cisgênera e rasuro a performance de masculinidade hegemônica, a qual imediatamente me interpela com um grunhido, marcando seu policiamento sobre meu corpo. O grunhido-enunciado da "arara" aponta indexicalmente (SILVERSTEIN, 1993; 2003) para a rasura que meu corpo instaura.

Nesse sentido, a interpelação que sofro não apenas me convoca "como sujeito" (ALTHUSSER, 1989, p. 98), mas me produz sujeito da dissidência do gênero/sexualidades. Para Butler (1997), a interpelação é um ato performativo o qual sustenta seu poder de ação sobre os sujeitos nas normas sociais e contextuais em que ela é realizada. A interpelação, desse modo, produz os sujeitos ao nomeá-los ou identificá-los, devido ao caráter citacional que configura o enunciado da interpelação.

Se por um lado Derrida desenvolve teorizações mais amplas no campo da linguagem e da significação, é Judith Butler (1990; 1993; 1997; 2003; 2010) que aprofunda as questões que antecipo na reflexão acima, sobre o corpo e as práticas de resistência que emergem no tensionamento com regimes de saber-poder-subjetividade hegemônicos. A filósofa e feminista estadunidense ao se engajar no debate sobre o domínio do gênero e do sexo ampliará o conceito de performatividade o qual terá implicações fundamentais sobre a produção do corpo como materialidade significante nos processos de produção de sujeitos. Se a ação está no centro de força do ato de fala, enquanto um dizer que é um fazer, esse entendimento será radicalizado ao colocar a iteração como força motriz da produção do sujeito do gênero que é efeito do discurso que opera numa complexa dinâmica de relações de saber/poder e regimes de verdade decorrentes.

\section{Performance, Sujeito, Corpo}


Para além de Austin e Derrida, é a influência de Michel Foucault (2000) que aprofunda a noção de performatividade presente nas teorizações de Butler (1990; 1997). Se o performativo opera com base na iterabilidade da linguagem, com potencial de produção de significados subversivos ou manutenção de sua aparente estabilidade, o funcionamento dos enunciados no domínio das formações discursivas ${ }^{5}$ adicionam complexidade aos processos implicados na produção de significação, do sujeito e da verdade.

Com base no entendimento Foucaultiano de discurso como conjuntos de enunciados que governam nossa condição de sujeitos (FOUCAULT, 1999), Butler (1990) constitui sua argumentação projetando essa compreensão também para a produção do gênero e do corpo. Enunciados emergentes em diferentes contextos de enunciação produzem formações discursivas, como a medicina, a sexualidade, a loucura etc. e são precisamente dessas formações discursivas reguladas por instituições e seus regimes de saber-poder em tempos históricos e políticos específicos, que os sujeitos são discursivamente constituídos (FOUCAULT, 1999; 2000; SALIH, 2015; ARAN; PEIXOTO Jr., 2007).

Ter esse entendimento em nossa atenção é fundamental uma vez que os significados e performances em movimento nas práticas sociais dos sujeitos não estão determinados a priori, mas são efeito de formações discursivas mais amplas, sustentadas por instituições sociais como a família, a igreja, a escola, a mídia, o Estado etc. as quais orientam nossas práticas. O sujeito de Butler (1990) é, sobretudo, o sujeito de Foucault (1999), sujeito a relações de saberpoder e regimes de verdade que constituem sua possibilidade e seu limite. Para Foucault, o poder não opera apenas na coação e dominação das subjetividades, mas é, precisamente, um poder produtivo na medida em que forja os sujeitos dentro dos mecanismos de disciplina e regulação que instaura e busca preservar (FOUCAULT, 1999; 2000).

É nesse sentido que as noções de ato de fala performativo de Austin (1990) e seu adensamento com base nos conceitos de citação e iterabilidade de Derrida (1991), e saberpoder de Foucault $(1996 ; 2000)$ encaminharão Butler a colocar a linguagem no protagonismo da produção de sujeitos do gênero e do corpo, engajando, assim, uma performatividade radical (PINTO, 2002; 2007).

O corpo, identificado como "uma fronteira variável, uma superfície cuja permeabilidade é politicamente regulada, uma prática significante dentro de um campo cultural” (BUTLER, 1990, p. 198) passa a ser entendido dentro das dinâmicas de regimes de

\footnotetext{
${ }^{5}$ Na definição de Foucault: "a formação discursiva se caracteriza não por princípios de construção, mas por uma dispersão de fato, já que ela é para os enunciados não uma condição de possibilidades, mas uma lei de coexistência, e já que os enunciados não são elementos intercambiáveis, mas conjuntos caracterizados por sua modalidade de existência. (FOUCAULT, 1997, p. 135)"
} 
saber-poder e verdade específicos. Com base nessa complexa dinâmica, para Butler, a linguagem opera em performance, um fazer que implica a um só turno o ato de corpo e o ato de fala. Conforme esclarece Pinto (2002),

Essa afirmação não cria, como se poderia esperar, uma dicotomia corpo/linguagem, mas, ao contrário, mostra que o efeito do ato de fala é operado ao mesmo tempo pelo que é dito, por quem diz e por como é dito como o corpo diz, como o enunciado diz. Os elementos que impulsionam sua marca no ato de fala operam numa imbricação irredutível. (PINTO, 2002, p. 106)

Com base nessa reflexão, no meu entendimento, corpo-linguagem-sujeito funcionam de modo articulado no fazer, na prática, e por isso operam imbricados, sendo a performance o lugar dessa ação. Orientado pela leitura de Problemas de Gênero (BUTLER, 1990), compreendo a performance como um fazer materialmente inscrito que faz aparecer o domínio da performatividade. Embora reconheça a leitura de Butler que distingue performance de performatividade, ou seja, que conceitua a performance como um ato deliberado, diferente da performatividade, que é um ato de reiteração de normas sociais, e por isso é condicionado; na minha leitura, argumento pela noção de que a performatividade sempre opera sobre as nossas ações enquanto sujeitos, sobre as nossas performances, sejam elas deliberadas ou "regimentadas". É precisamente nessa articulação que a linguagem assume protagonismo nos processos de produção de significados e de mundos sociais, em que o corpo, em performance, se torna efeito e agente desses densos processos.

Com essa reflexão sob minha atenção, e ciente de que essa distinção performatividade/performance muitas vezes ainda é fonte de confusões, insisto no entendimento de que a performatividade sempre opera sobre as nossas ações enquanto sujeitos, seja quando estamos "forjando" ou "encenando artisticamente" um comportamento social, seja quando estamos agindo enquanto sujeitos de normas sociais especificas que nos governam, "inconscientes" da lei que nos faz sujeitos.

Assim, a performance viabiliza e visibiliza a performatividade, na medida em que é a performance que faz operar no/com o corpo-fala, os regimes regulatórios e normas sociais que seduzem sujeitos a se imaginarem como sendo possuidores de um gênero particular. Desse modo, utilizo a performatividade como um conceito teórico que ajuda a pensar a ação social dos sujeitos e suas práticas, que se dão em performance. Reconhecer que não estamos adequados à norma é o que nos faz identificar a lei que nos governa, o que nos interpela diante do saber/poder que nos subjetiva, mobilizando reflexividades. 
Um dos regimes de verdade que tem se imposto sobre os sujeitos e seus corpos é o da heterossexualidade compulsória e masculinista, um domínio do saber-poder hegemônico que tem regimentado o binarismo de gênero, e a matriz de inteligibilidade que nos conduz a reconhecer o sexo biológico como natural a um determinado gênero (BUTLER, 1990).

Conforme enuncia Preciado, "pênis e vaginas são biocódigos de regimes de poder e conhecimento, reguladores ideais, ficções biopolíticas que encontram seu suporte somático na subjetividade individual" (PRECIADO, 2018, p. 112-113). Ao identificar que o corpo não existe socialmente antes de já ter sido generificado e sexualizado, tendo em vista o nascimento biológico do corpo, e sua inscrição como sujeito desde a primeira interpelação social que sofre, por conta dos significados culturais projetados sobre sua anatomia, Butler (2003) argumenta que

Considerada coletivamente, a prática repetida de nomear a diferença sexual criou essa aparência de divisão natural. A "nomeação" do sexo é um ato de dominação e coerção, um ato performativo institucionalizado que cria e legisla a realidade social pela exigência de uma construção discursiva/perceptiva dos corpos, segundo os princípios da diferença sexual. (...) 'somos obrigados, em nossos corpos e em nossas mentes, a corresponder, traço por traço, à idéia de natureza que foi estabelecida para nós... 'homens' e 'mulheres' são categorias políticas, e não fatos naturais'. (BUTLER, 2003, p. 168)

Com base na citação acima, passamos a entender gênero e sexo como categorias fundamentais que mobilizam os debates empreendidos por Butler (1990; 1993; 1997; 1998; 2003; 2010) e outras feministas (SALIH, 2015) que têm se dedicado a problematização do gênero dentro da luta feminista e diante do projeto heterossexual masculinista compulsório estruturante da sociedade patriarcal contemporânea (NARVAZ; COLLER, 2006). Uma vez que o sexo e o gênero são construções performativas produzidas dentro da matriz heterossexual, será o corpo o lugar de inscrição do gênero e do sexo como materialidades significantes.

É desse modo que a performatividade deixa ver sua lei de fazer na performance que, via citação/iterabilidade, faz parecer naturais os significados e as normas sociais instituídas histórica, política e culturalmente. A performance visibiliza os estilos da carne, inscreve significados sobre a materialidade anatômica do corpo, nomeia a ordem dos sexos, e assim, produz o sujeito, afeito às normas ou dissidente delas.

Com base na pesquisa etnográfica que localiza este debate, chamo atenção para o relato de um dos sujeitos do estudo, o qual enunciou diversas vezes as coerções operadas 
sobre seu corpo quando criança, pela própria mãe, devido às performances de feminilidade que encenava. "Pequenas" agressões físicas nas mãos e nas pernas, além de uma série de proibições, iam moldando a postura de "homem", ou seja, a performance de masculinidade hegemônica que ele deveria aprender a performar (SENA, 2020).

Desses domínios generificados, observo que emergem novas complexidades à medida que se dá o nascimento social do sujeito em outras esferas da vida em sociedade. A classe social, a geração, a religião, o tempo histórico, o espaço geográfico, por exemplo, radicalizam a produção do sujeito, que passa a demandar sua ação nos limites regulatórios das relações de saber-poder instituídas em seus mundos sociais.

Esse entendimento condensa "a radicalidade" da performatividade na produção de significação nas práticas sociais. Em um processo continuo de repetição de significados sedimentados na cultura somos produzidos sujeitos:

atos, gestos e desejo produzem o efeito de um núcleo ou substância interna, mas o produzem na superfície do corpo, por meio do jogo de ausências significantes, que sugerem, mas nunca revelam, o princípio organizador da identidade como causa. Esses atos, gestos e atuações, entendidos em termos gerais, são performativos, no sentido de que a essência ou identidade que por outro lado pretendem expressar são fabricações manufaturadas e sustentadas por signos corpóreos e outros meios discursivos. $\mathrm{O}$ fato de o corpo gênero ser marcado pelo performativo sugere que ele não tem status ontológico separado dos vários atos que constituem sua realidade (BUTLER, 2003, p. 194)

Ao argumentar pelo entendimento de que o corpo biológico é uma construção discursiva, a proposição teórica de Butler (1990) implica a desconstrução da ontologia de gênero e do sexo biológico como naturais, noção que fissura dicotomias clássicas como a de natureza/cultura. Nesse sentido, podemos afirmar que toda construção do que seja natural é desde já produzido no discurso, na linguagem, sob o regime de forças, sobretudo políticas.

Este aspecto nos ajuda a refletir sobre uma série de naturalizações que regimentam as práticas sociais de sujeitos em diferentes contextos socioculturais. Os saberes considerados leigos (FERREIRA, 2016), por exemplo, e suas complexas articulações com diferentes esferas das atividades humanas (religião, jurisdição, Estado, família, escola etc.), têm papel crucial na produção de sujeitos e de contextos de opressão, assim como, de resistência.

O corpo, condicionado pelos marcadores semiótico-sociais subjetivantes que o regimentam, pelos domínios de saber-poder-subjetividade que produzem regimes de verdades 
PERcursos Linguísticos • Vitória (ES) •v. 10 •n. 25 • 2020 • ISSN: 2236-2592 • Dossiê:

Discursos de resistência e corpos (re)existentes

sobre ele, também é o corpo que age no limite dessas circunstâncias, de onde pode operar subversivamente e construir resistências. É ao debate desse ato de resistência diante das normas, entendido como um efeito do tensionamento entre o desejo e o exercício de poder, que a próxima seção se dedica.

\section{Desejo, Agência, Resistência}

Meu interesse central neste debate, com base no que venho argumentando sobre a performatividade, é precisamente a capacidade de agência e a produção de resistência que emerge desses processos de saber-poder-subjetividade articulados na linguagem, em performance. Se a capacidade de agência se localiza na zona de produção do desejo, conforme aprofundo a seguir, a resistência é um domínio de força possível o qual produz diferença diante do quadro regulatório que constitui os sujeitos.

Foucault previa que dentro dos regimes de poder já se constituía também a condição de resistência diante de tais normas: "onde há poder, há resistência”, argumenta Foucault (1999, p. 105). Esse entendimento será recuperado por Butler, e aprofundado na medida em que a filósofa e teórica feminista passa a se preocupar com o modo de articulação da agência dentro desses regimes regulatórios, considerando, então, o domínio da consciência do sujeito, ou seja, a formação da identidade e do ego, e os densos processos de constituição da subjetividade, especialmente a identidade de gênero e do corpo generificado. Conforme afirma Butler:

Se a subversão for possível, será uma subversão a partir de dentro dos termos da lei, por meio das possibilidades que surgem quando ela se vira contra si mesma e gera metamorfoses inesperadas. $\mathrm{O}$ corpo culturalmente construído será então libertado, não para seu passado "natural", nem para seus prazeres originais, mas para um futuro aberto de possibilidades culturais. (BUTLER, 2003, p. 139).

É com base nessa compreensão que Butler (1990) desenvolveu sua teorização sobre o processo de incorporação ${ }^{6}$ (BUTLER, 1990, p.87), o qual inscreve na superfície do corpo a identidade de gênero, apontando, a partir desse domínio, como a proibição é geradora do desejo, desejo que mobiliza a capacidade de agência do sujeito diante das normas que o coagem e constituem. Conforme aponta Furlin (2013), para debater as categorias da agência e

\footnotetext{
${ }^{6}$ No original "the mask is take on through the process of incorporation which is a way of scribing and then wearing in melancholic identification in and on the body" (BUTLER, 1990, p. 50)
} 
PERcursos Linguísticos • Vitória (ES) •v. 10 •n. 25 • 2020 • ISSN: 2236-2592 • Dossiê:

Discursos de resistência e corpos (re)existentes

da resistência, é necessário entender o desejo, conceito fundamental envolvido na formação do ego e do modo de regulação e resistência presentes na formação da identidade de gênero.

Fortemente influenciada pelas teorizações de Freud(1996) sobre a formação da identificação, Butler produz sua argumentação com base na noção de tabu contra a homossexualidade, correlata à noção de tabu contra o incesto, previsto em Freud (1996). Para Butler (1990, p. 99-100), o tabu contra a homossexualidade antecede ao tabu contra o incesto, e é precisamente na proibição gerada diante desse tabu, que o gênero é produzido, ganhando materialidade inteligível no corpo.

Esse domínio de formação da identidade frente ao tabu configura precisamente o conceito de identificação (FREUD, 1996, p. 28) o qual decorre da condição melancólica ${ }^{7}$ instaurada no sujeito, que ao invés de superar ou aceitar uma perda ou proibição, a condição melancólica internaliza a perda no ego, produzindo uma identificação com ela. Ao processo de construção da identificação, Freud chama introjeção (1996, p. 104). Na argumentação de Butler, ao fazer a leitura de Freud, a introjeção não será o único modo de construção da identificação, propondo, então, a noção de incorporação que consiste precisamente na produção da identificação inscrita na superfície do corpo.

Para Freud (1996), a estrutura do ego será toda melancólica, entendendo que o ego é produzido pela identificação com as proibições a que é submetido desde suas primeiras socializações. Essa estruturação melancólica do ego se dá no processo da formação do ego a partir do desejo primitivo que a criança desperta pela mãe ou pelo pai. Em resposta ao tabu contra o incesto, a criança substitui o desejo por um dos progenitores pela identificação com um deles. A esse desejo primitivo Freud chama disposições, sem dar explicação precisa do que seria, mas relacionando-as, ainda que de modo hesitante, às disposições sexuais congênitas (BUTLER, 1990; SALIH, 2015).

Butler, interessada pelas disposições, mas rejeitando completamente a noção de disposição sexual congênita, inverte a proposição de Freud, afirmando que o desejo primitivo é posterior a identificação (BUTLER, 1990, p.100-101), ou seja, o desejo emerge das proibições/regimentações envolvidas no processo de identificação em que "o ego é, então, um depósito de todos os desejos que ele teve de abandonar" (SALIH, 2015, p. 76). Com isso, Butler quer produzir o entendimento de que aqui a criança, primeiro a) reconhece/aprende a lei, b) processo no qual ela se manifesta desejante, em seguida c) se sujeita à sua norma ao reconhecer o tabu (contra a homossexualidade e contra o incesto), c)

\footnotetext{
${ }^{7}$ Segundo Freud (1996) a melancolia é a sensação de uma perda sem necessariamente se ter conhecimento do que foi perdido.
} 
instaura a melancolia pela proibição e, em decorrência, d) produz a identificação seja e) introjetando no ego o objeto/desejo perdido/proibido, seja f) incorporando na superfície da carne. Nas palavras de Butler, "a identidade de gênero parece ser primariamente a internalização de uma proibição que se mostra formadora de identidade" (BUTLER, 1990, p. 79).

Com base nas reflexões teóricas de Butler sobre a produção da identidade, construo o entendimento de que esses processos se estendem a outras dimensões de nossa subjetividade, e se darão continuamente ao longo do nascimento social dos sujeitos nos diferentes processos de socialização que só cessam com o fim da vida. Quero dizer com isto que nossa condição de sujeitos do gênero/sexualidades, por exemplo, será sempre produzido na relação tensionada pelas normas que nos coagem/regimentam, e as condições de resistência que seus limites viabilizam.

Desse modo, o sujeito não é nem totalmente livre e dono de si, nem um prisioneiro sem algumas alternativas diante do poder que opera sua sujeição. Do mesmo modo, somos sujeitos do desejo, essa força emergente das coações que se impõem dentro de uma determinada ordem social sobre nós, e que desperta nossa reflexividade e agentividade diante dos regimes que nos coagem/interpelam. Na leitura de Furlin sobre o pensamento de Butler

a consciência reflexiva tem um diferencial, por estar pautada no desejo humano, que pode se manifestar dentro dos mais diferentes aspectos da ordem social, sempre que houver um poder normativo que limita a ação do sujeito. Essa ação pode estar localizada na ordem do desejo erótico, do desejo de reconhecimento social, do desejo de poder político, do desejo de inserção social e, assim, poderíamos nomear tantos outros desejos que fazem com que se ative a consciência do limite (FURLIN, 2013, p. 401)

Por fim, o desejo como demanda dos regimes de regulação da ordem social e do processo de constituição da pisque humana, o que envolve proibições, identificações, agência e resistência, nos mobiliza em dinâmicas performativas e, portanto, de linguagem, possibilitando uma condição de reflexividade diante da norma que nos coage e interpela. Nas palavras de Butler (2010, p. 25) “o sujeito é ele próprio uma ambivalência, pois surge simultaneamente como efeito de uma potência anterior e como condição de possibilidade de uma forma de potência radicalmente condicionada". Ou seja, podemos dizer que a capacidade de agência, instaurada no limite friccional em que se encontra a produção do desejo e o exercício do poder, produz a resistência. 
PERcursos Linguísticos • Vitória (ES) •v. 10 •n. 25 • 2020 • ISSN: 2236-2592 • Dossiê:

Discursos de resistência e corpos (re)existentes

\section{O protagonismo da linguagem}

Argumentar pelo protagonismo da linguagem com base em uma visada relativista não implica em apregoar uma nova verdade para ser simplesmente seguida, mas nos possibilita o exercício de confrontar uma série de universalismos que visões essencialistas estabeleceram sobre a linguagem e que a vida contemporânea tem nos impelido a questionar e a rever. Assim, a visada pragmática, ao dar relevo aos usos e às práticas dos sujeitos nos complexos contextos da vida social, engaja um importante avanço em termos de reflexividade, da capacidade de nos pensarmos em nossas práticas, processo que se dá na linguagem e com a linguagem.

É de grande relevância enfatizar o domínio da reflexividade, pois é com ele que se torna viável questionarmos as relações de saber-poder-subjetividade que constituem nossa experiência social, que nos constituem sujeitos do gênero/sexualidades, no corpo e na resistência. Nesse sentido, a teoria performativa de Judith Butler constribui de modo determinante nesse exercício de imaginar alternativas diande de regimes de verdade que geram sofrimento humano. Ela aprofunda a reflexão sobre como a performance não está condicionada a repetição/citação de normas instituídas, mas viabiliza possibilidade de agência, de agir reflexivamente e contestar os regimes de saber-poder que nos coagem.

A questão da verdade e do sentido passam a ser vistas em constante disputa e compreendidas como continuamente provisórias. É assim que os discursos sobre a verdade, os processos semióticos que tornam os corpos inteligíveis e as práticas de resistência que fissuram as estruturas cristalizadas do poder nos conduzem à compreensão do protagonismo da linguagem em tais relações.

A partir de Foucault (1996; 1999), o entendimento de que a verdade é efeito de constantes disputas por significação, nos diferentes domínios das formações discursivas e da história, consolida uma visada não-essencialista da liguagem também presente nos conceitos de différance, citação e iterabilidade de Jacques Derrida (1991; 1973), conforme debati. Esses domínios, articulados na argumentação de Bulter sobre como se dá o processo de identificação na construção de nossas subjetividades sexo-generificadas, em nível macro e microsocial, se materializam no conceito de performatividade o qual ganha vida e forma nas práticas sociais por meio da noção de performance. É nesse sentido que podemos afirmar que Butler opera uma radicalização na teoria performativa de Jhon Austin (1990), trazendo 
PERcursos Linguísticos • Vitória (ES) •v. 10 •n. 25 • 2020 • ISSN: 2236-2592 • Dossiê:

Discursos de resistência e corpos (re)existentes

contribuições fundamentais para a compreensão da linguagem, não apenas na produção de significados, mas de modo determinante na produção do corpo e das práticas de resistência.

\section{Rereferências}

ALTHUSSER, Louis. Aparelhos Ideológicos do Estado: nota sobre aparelhos ideológicos do Estado. Portugal: Editorial Presença. Brasil: Martins Fontes: 1989.

ARAN, Márcia; PEIXOTO JÚNIOR, Carlos. Subversões do desejo: sobre gênero e subjetividade em Judith Butler. Cadernos Pagu, n. 28, p. 129-147, janeiro-junho de 2007.

AUSTIN, John. Quando dizer é fazer. Palavras e Ação. Tradução de Danilo Marcondes de Souza Filho. Porto Alegre: Artes Médicas, 1990.

BARRETO, Victor. Vamos fazer uma sacanagem gostosa? Uma etnografia da prostituição masculina carioca. Dissertação (Mestrado em Antropologia) - Programa de Pós-graduação em Antropologia, Universidade Federal Fluminense, Niterói - RJ, 2012.

BASTOS, Liliana; BIAR, Liana. Análise de narrativa e práticas de entendimento da vida social. DELTA [online]. vol.31, n. spe, p. 97-126, 2015.

BAUMAN, Richard; BRIGGS, Charles. Voices of modernity: language ideologies and the politics of inequality. Cambridge: Cambridge University Press, 2003.

BAUMAN, Zigmund. Vida para consumo. Trad. de Carlos Alberto Medeiros. Rio de Janeiro: Jorge Zahar Ed., 2008.

BONFANTE, Gleiton. Erótica dos Signos nos Aplicativos de Pegação: processos multissemióticos em performances íntimo espetaculares de si. Dissertação (Mestrado em Linguística Aplicada) - Programa Interdisciplinar de Pós-graduação em Linguística Aplicada, UFRJ, Rio de Janeiro, 2015.

BORBA, Rodrigo. (Des)aprendendo a "ser": trajetórias de socialização e performances narrativas no processo transexualizador. Tese (Doutorado em Linguística Aplicada) Programa Interdisciplinar de Pós-graduação em Linguística Aplicada, UFRJ, Rio de Janeiro, 2014.

BORBA, Rodrigo. Linguística Queer: uma perspectiva pós-identitária para os estudos da linguagem. Revista Entrelinhas - Vol. 9, n. 1 (jan./jun.), p. 91-107, 2015.

BRAZ, Camilo. À meia-luz...: uma etnografia imprópria em clubes de sexo masculinos. Tese (Doutorado em Ciências Sociais) - Programa de Pós-graduação em Ciências Sociais, Universidade Estadual de Campinas, Campinas, 2010.

BUTLER, Judith. Gender Trouble: feminism and the subversion of identity. Routledge: New York, 1990. 
PERcursos Linguísticos • Vitória (ES) •v. 10 •n. 25 • 2020 • ISSN: 2236-2592 • Dossiê:

Discursos de resistência e corpos (re)existentes

BUTLER, Judith. Problemas de Gênero: feminismo e subversão da identidade. Trad. Renato Aguair. Rio de Janeiro: Civilização Brasileira, 2003.

BUTLER, Judith. Bodies that Matter: On the Discursive Limits of 'Sex'. New York and London: Routledge, 1993.

BUTLER, Judith. Excitable Speech. A politics of performative. Routledge. New York \& London, 1997.

Butler. Judith. Mecanismos psíquicos del poder: Teorías sobre la sujeción. 2 ed. Madrid, Ediciones Cátedra, 2010.

CAMARGO, Mabia. "Acuenda esse bajubá!": indexicalidades e interseccionalidades nas performances narrativas de uma travesti quilombola. Tese (Doutorado em Linguística Aplicada) - Programa Interdisciplinar de Pós-graduação em Linguística Aplicada, UFRJ, Rio de Janeiro, 2019.

CAMARGO JUNIOR, Kenneth. Aids and aids according to the sciences. História, Ciências, Saúde - Manguinhos, I p. 35-60, jul.-oct., 1994.

DERRIDA, Jacques. Margens da Filosofia. Campinas - SP: Papirus, 1991.

DERRIDA, Jacques. Gramatologia. São Paulo, Perspectiva, Ed. da Universidade de São Paulo, 1973.

FABRÍCIO, Branca. Lingüística Aplicada como espaço de desaprendizagem: redescrições em curso. In: Luiz Paulo da Moita Lopes. (Org.). Por uma lingüística aplicada INdisciplinar. São Paulo: Parábola Editorial, 2006, p. 45-65.

FERREIRA, Maria. Entre redes de discursos e de pesca: performances narrativas de mulheres pescadoras em Arraial do Cabo. Tese (Doutorado em Linguística Aplicada) Programa Interdisciplinar de Pós-graduação em Linguística Aplicada, UFRJ, Rio de Janeiro, 2016.

FOUCAULT, Michel. A ordem do discurso. Tradução de Laura Fraga de Almeida Sampaio.

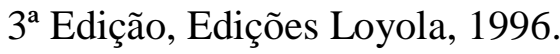

FOUCAULT, M. A arqueologia do saber. Rio de Janeiro: Forense Universitária, 1997.

FOUCAULT, Michel. Microfísica do poder. Organização e tradução de Roberto Machado. Rio de Janeiro: Edições Graal, 4ª ed. 1984.

FOUCAULT, Michel. História da Sexualidade I: A vontade de saber. 13. ed. Rio de Janeiro: Graal, 1999.

FOUCAULT, Michel. Em defesa da sociedade: curso no College de France. Tradução de Maria Ermatina Galvão. São Paulo: Martins Fontes, 2000.

FREUD, Sigmund. O ego e o id e outros trabalhos. Rio de Janeiro: Imago, 1996. 
PERcursos Linguísticos • Vitória (ES) •v. 10 •n. 25 • 2020 • ISSN: 2236-2592 • Dossiê:

Discursos de resistência e corpos (re)existentes

FURLIN, Neiva. Sujeito e agência no pensamento de Judith Butler: contribuições para a teoria social. Sociedade e Cultura, n.16, p. 395-403, 2013.

GAZPAR NETO, Verlan. Na pegação: Encontros homoeróticos masculinos em Juiz de Fora. Dissertação (Mestrado em Antropologia) - Programa de Pós-graduação em Antropologia, Universidade Federal Fluminense, Niterói - RJ, 2008.

GIDDENS, Anthony. As consequências da modernidade. São Paulo: Editora Unesp, 1991.

GUIMARÃES, Thayse. Embates entre performances corpóreo-discursivas em trajetórias textuais: uma etnografia multissituada. Tese (Doutorado em Linguística Aplicada) - Programa Interdisciplinar de Pós-graduação em Linguística Aplicada, UFRJ, Rio de Janeiro, 2014.

GUIMARÃES, Thayse; MOITA LOPES, Luiz Paulo da. Trajetória de um texto viral em diferentes eventos comunicativos: entextualização, indexicalidade, performances identitárias e etnografia. ALFA: revista de linguística (unesp. impresso), vol. 61, p. 11-33, 2017.

LOXLEY, James. Performativity. Nova York: Routledge, 2007.

MARTINS, Helena. Três caminhos da Filosofia da linguagem. In: MUSSALIM, F.; BENTES, A. Introdução à linguística: fundamentos epistemológicos. São Paulo: Cortez, 2004, vol. 3, p. 439-473.

MIGNOLO, Walter. Desobediência Epistêmica: a opção descolonial e o significado de identidade em política. Cadernos de Letras da UFF - Dossiê: Literatura, língua e identidade, n. 34, p. 287-324, 2008.

MOITA LOPES, Luiz Paulo da. Pesquisa interpretativa em linguística aplicada: a linguagem como condição e solução. DELTA, São Paulo, vol. 10, n. 2, p. 329-338, 1994.

MOITA LOPES, Luiz Paulo da. Identidades Fragmentadas: a construção discursiva de raça, gênero e sexualidade em sala de aula. Campinas: Mercado de Letras, 2002.

MOITA LOPES, Luiz Paulo da. (Org.) Por uma Linguística Aplicada Indisciplinar. Parábola Editorial: São Paulo, 2006.

MOITA LOPES, Luiz Paulo da. Ideology in research methodology. In: Carol A. Chapelle. (Org.). The Encyclopedia of Applied Linguistics. 1ed. Nova York: Wiley Blackwell, 2012, p. 223-224.

MOITA LOPES, Luiz Paulo da. Português no Século XXI: cenário geopolítico e sociolinguístico. 1. ed. São Paulo: Parábola, 2013.

NARVAZ, Martha; COLLER, Sílvia. Famílias e patriarcado: da prescrição normativa à subversão criativa. Psicologia \& Sociedade; vol.18, p. 49-55; jan/abr. 2006.

OTTONI, Paulo. John Langshaw Austin e a visão performativa da linguagem. Revista D.E.L.T.A., vol. 18, p. 117-143, 2002.

PEIRCE, Charles. Semiótica. São Paulo: Perspectiva, 1977. 
PERcursos Linguísticos • Vitória (ES) •v. 10 •n. 25 • 2020 • ISSN: 2236-2592 • Dossiê:

Discursos de resistência e corpos (re)existentes

PÉREZ NAVARRO, Pablo. Del texto al sexo: Judith Butler y la performatividad. 1. ed. Madri: Egales, 2008.

PINTO, Joana. Performatividade Radical: ato de fala ou ato de corpo? Gênero. vol. 3, n.1, p. 101-110. 2sem. 2002.

PINTO, Joana. Conexões teóricas entre performatividade, corpo e identidades. DELTA. Documentação de Estudos em Lingüística Teórica e Aplicada, vol. 23, p. 1-26, 2007.

PINTO, Joana. O corpo de uma teoria: marcos contemporâneos sobre os atos de fala. Cadernos Pagu (UNICAMP. Impresso), vol. 33, p. 117-138, 2009.

PINTO, Joana. De diferenças e hierarquias no quadro Adelaide às análises situadas e críticas na linguística aplicada. D.E.L.T.A., vol. 31, p. 199-221, Edição especial, 2015.

POCAHY, Fernando. Entre vapores e dublagens: dissidências homo/eróticas nas tramas do envelhecimento. Tese (Doutorado em Educação) - Programa de Pós-graduação em Educação, Universidade Federal do Rio Grande do Sul, Porto Alegre, 2011.

PRECIADO, Paul. Texto Junkie: sexo, drogas e biopolítica na era farmacopornográfica. São Paulo: n-1, 2018.

SANTOS, Boaventura. Um discurso sobre as Ciências Sociais. 5. ed. São Paulo: Cortez, 2008.

SANTOS FILHO, Ismar. A construção discursiva de masculinidades bissexuais: um estudo em linguística queer. Tese (Doutorado em Letras) - Programa de Pós-graduação em Letras, Universidade Federal de Pernambuco, Recife, 2012.

SALIH, Sara. Judith Butler e a Teoria Queer. Belo Horizonte: Autentica, 2015.

SENA, José. Posicionamentos interacionais mobilizados na performance de gênero/sexualidades e soropositividade de um sujeito focal. In: I Simpósio de Gênero e Diversidade, Pelotas. Debatendo Identidades. Pelotas: UFPel, vol. 1. p. 577-598, 2016.

SENA, José. Apontamentos microanalíticos sobre a produção de subjetividades: entendimentos sobre sexualidades e HIV. In: FERRARI, A.; POLATO, Castro. (Org.). Estudos sobre a diversidade Sexual e de Gênero: ABEH e a Construção de um Campo de Pesquisa. 1ed. Campina Grande/PB: Realize Editora, 2017, p.1075-1082.

SENA, José. Entextualização, Indexicalidade e a Produção Discursiva do Cuidado à Saúde Sexual LGBTI+ no Interior da Amazônia Oriental. RIBANCEIRA, vol. 4, p. 04-19, 2018.

SENA, José. Corpos Dissidentes e Biopolítica na Amazônia Atlântica: disputas metapragmáticas no cuidado em saúde. Tese (Doutorado em Linguística Aplicada) Programa Interdisciplinar de Pós-graduação em Linguística Aplicada, Universidade Federal do Rio de Janeiro, Rio de Janeiro, 2020. 
PERcursos Linguísticos • Vitória (ES) •v. 10 •n. 25 • 2020 • ISSN: 2236-2592 • Dossiê:

Discursos de resistência e corpos (re)existentes

SILVA, Cássio. Alívio Incontido: êxtase, desejo e sexualidade em uma feira livre, BragançaPA. Dissertação (Mestrado Interdisciplinar em Linguagens e Saberes) - Programa de Pósgraduação em Linguagens e Saberes na Amazônia, Universidade Federal do Pará, Bragança, 2015 .

SILVERSTEIN, Michael. Metapragmatic discourse and metapragmatic function. In: LUCY, John (Ed.). Reflexive language, reported speech and metapragmatics. Cambridge: Cambridge University Press, 1993. p. 33-58.

SILVERSTEIN, Michael. Indexical order and the dialectics of sociolinguistic life. Language \& Communication, vol. 23, p.193-229, 2003.

SOUZA, Camilla. Relações de gênero em Bacuriteua (PA): imaginário do homoerotismo masculino entre catadores de caranguejo. Dissertação (Mestrado Interdisciplinar em Linguagens e Saberes) - Programa de Pós-graduação em Linguagens e Saberes na Amazônia, Universidade Federal do Pará, Bragança, 2013.

SOUZA, Tedson. Fazer banheirão: as dinâmicas das interações homoeróticas nos sanitários públicos da estação da lapa e adjacências. Dissertação (Metrado em Antropologia) - Programa de Pós-graduação em Antropologia, UFBA, Salvador, 2012.

TREICHLER, Paula. AIDS, homophobia and biomedical discourse: an epidemic of signification. Cultural Studies, vol. 1, n. 3, p. 263-395, 1987.

VOLOCHINOV, Valentin. Marxismo e filosofia da linguagem: problemas fundamentais do método sociológico na ciência da linguagem. 9ª edição. São Paulo: Hucitec, 1997.

WORTHAM, Stam. Narratives in action. A strategy for research and analysis. Teachers College: Columbia University, 2001. 